\title{
THE OPERATION OF AN EMERGENCY MEDICAL DEPARTMENT IN A COUNTY HOSPITAL FROM A LOGISTIC POINT OF VIEW \\ ${ }^{1}$ G. Markó, ${ }^{2} J$. Gál \\ ${ }^{1}$ Fejér County Saint George University Teaching Hospital, Seregélyesi út 3, 8000, Székesfehérvár, Hungary, e-mail: markogabor88@gmail.com \\ ${ }^{2}$ University of Szeged Faculty of Engineering, Mars ter 7, 6724, Szeged, Hungary, e-mail: galj@mk.u-szeged.hu
}

\begin{abstract}
ABSTARCT
The purpose of this article is to give an overview of the actual emergency medical attendance through an exemplary hospital in Hungary, highlighting its possible imperfections which could perhaps be improved through further structural developments. In order to be expressive, the article follows through the journey of two nominal patients who turned up in the emergency department of the hospital. The importance of this topic is expressed by the fitful judgment of the emergency attendance. Emergency service had already existed in the United States, only later then did the oneentrance service system start to develop Hungary. In some places this system has been working well for decades, but for instance at the University of Szeged - due to the uncertain judgment of the system - the construction is just being finalized, right at the time when such studies are published that question the reason of existence of the emergency departments - at least in their actual form.
\end{abstract}

Keywords: emergency, logistics, hospital, Székesfehérvár, medical care, SBO EMD

\section{INTRODUCTION}

The annual patient traffic of the department of emergency medical care at Fejér Megyei Szent György Egyetemi Oktató Kórház (Fejér County Saint George University Teaching Hospital) [7] in Székesfehérvár is 33.000 persons, as it can be read on the hospital's website.

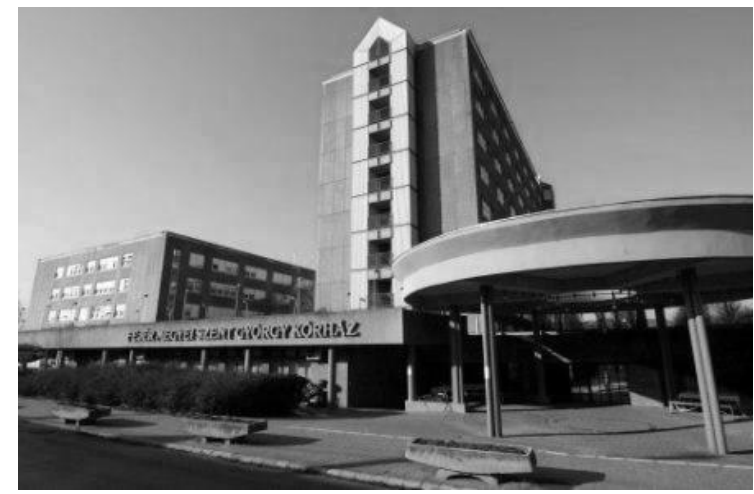

Figure 1. Fejér County Saint George University Teaching Hospital [7]

The source states that the total number of the population attended by it is 420.000 persons. It can be concluded from these two numbers that each twelth person of the population concerned, which is $4,2 \%$ of the country's total population visit the emergency unit every year. According to the data it means 92 patients daily, around the clock, let it be a weekday, weekend or holiday. However, this number is experienced to show an outdated state. In the last six months or year there was hardly a day when the patient traffic was under a hundred. The number of the staff for this number of patients is distributed in the following way. Three of four surgeries work steadily. There is a doctor and an assistant in each of them. As a regular basis, in the fourth surgery there is a doctor in the most frequented period from the aspect of patient traffic: between noon and eight p.m. This time one of the assistants, for practical reasons the one in the middle surgery, works both in his/her own and in the fourth surgery, too. To understand this logic we are sketching the spatial location of the department, especially the surgeries. Coming from the entrance the doors of three surgeries open on the left, while the fourth from the right. The three surgeries on the left are joined by doors. So, when the fourth surgery operates actively, the temporary lack of the nurse in the middle surgery is compensated by the two assistants in the side surgeries. The triage nurse (expert in the first-aid rescue who assesses the general status) is the organic part of the staff. Besides doctors and nurses, 
it would be fairly difficult to define the number of staff because they do not belong to the department directly. The hospital porters are assigned centrally but they, together with the cleaning staff, work in a continuous shift of $0-24$. In case of a patient traffic of this kind it can be stated with reason that the department can work only in a well-organized structure which has not only financial and human resources conditions. It is also a fluently operating logistic system which, in this case, is not employed in securing pharmaceutical products and appliances though it is of the same importance, it is not specific from the view of the department of emergency medical care-but it sorts out the patients coming. The importance of the topic is emphasized not only because of the suitable use of hospital resources but it is underlined from the patient's aspect, as well, since the emergency unit - 'nomen est omen' - gives a quick treatment, even though originally the name itself would not refer to it. It can be concluded that it generates of dissatisfaction of high level if the patient has to wait long hours in the department waiting room.

\section{THE SUBJECT IN DETAILS}

The task of the Emergency Medical Department /EMD/ (in Hungarian Sürgősségi Betegellátó Osztály /SBO/) [8] - which has been formulated by themselves for themselves, is 'to accept patients with or without a referral, arriving either on foot or in ambulance twenty-four hours a day. Regardless of the referral or the way of the arrival the EMD complete an assessment of general status.' It also means that for the department this assessment, apart from the patient's status (explained later), is absolutely a loss of resources either in money, in human resources or in time, even though it is not in unit or the same degree. To sort out the cases which are more urgent than the other urgent or the totally groundless ones it requires highly-qualified experts with serious experiences. First, we are aiming to show the way in two separate fictitious cases which the patient go through until he/she leaves the department [5].

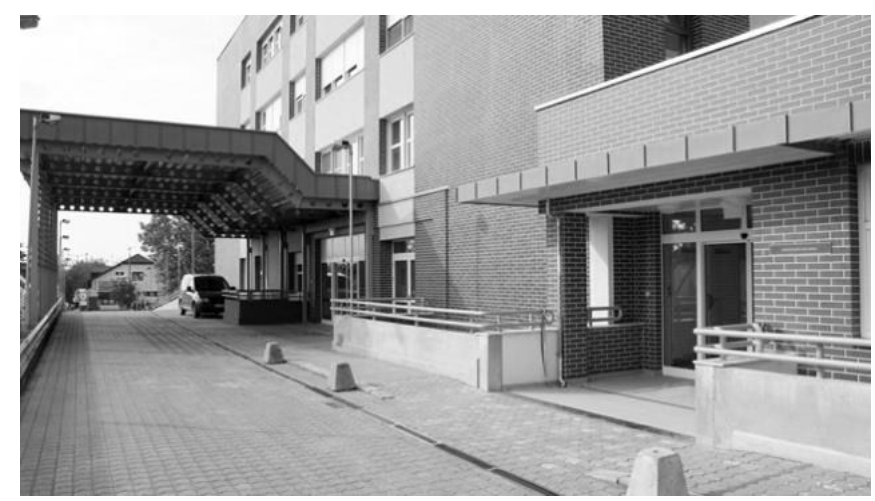

Figure 2. The entrance to EMD [8]

\subsection{The first case}

The first case is a young female patient in her thirties whose stomach starts to ache at home on Friday. The painkiller stops the stomachache at home but it reappears again and again during the weekend. The pain is durable first with one dose of painkillers and then with a double dose, so she spends her time with her family comfortably in an armchair. Then, on Monday morning when she wants to go to work her pain is still there which disturbs her in her activities so the 'well-informed' woman, who knows the tasks of the emergency department fairly well, decides to go to the EMD of the hospital. She leaves her home accompanied with her partner by car; the parking lot is about 150 meters away from the hospital, so they have to walk to the entrance. Entering the building they go to the reception right next to the entrance. Here, the patient gives her social security card to the officer sitting in front of the computer, and then they are asked to sit down in the waiting room. At 8.30 a.m. on Monday morning there are around 10-15 patients together with their relatives in the waiting room. In the meantime, the details about the patient are entered into the computer. So far, there is no information about it, it should be waited. The door of the triage room opens, the patient is called. The woman enters, and the assistant there asks her what the matter is. Her name, the date of birth, the security card number are written on the left upper corner of an envelope, which will contain every single document of the patient, the arrival time in the middle, while the complaint in the 
right upper corner. According to the patient's story the following sentences are written there:' Stomachache for 3 days. No vomits. No diarrhea [3]. After a few compulsory questions or in the meantime, regarding the number of patients in the waiting room, the nurse does the ECG which she puts into the envelope, measures the patient's oxygen saturation and blood pressure which values are written on the envelope. Then it is followed by the most important mark which is written next to the previous data, under the arrival time: IV. It is the triage nurse's task to sort out the patients on the basis of the questions and basic parameters. The cases which need immediate treatment belong to group me, while the not so urgent ones to group IV. Cases between them belong to groups II or III. After that our female patient is asked to take a seat in the waiting room while the triage nurse carries the envelope into one of the central surgeries. By 'central' I mean that from this surgery the doctors can enter two of the four ones, so it is easily accessible for them. Here, the nurse puts down the envelope on the pile of the ones marked with IV. The patient has to wait until one of doctors seizes the envelope with her name on it and takes it into his/her own surgery and asks her to enter there. So, it is important to know the logistics of envelope picking. From this aspect the complaints written on the envelope, blood pressure, oxygen saturation or the age of the patient are not important. There are two factors which the doctor weighs: the number which shows the state of urgency and the arrival time. To make the things simpler, we disregard the case that if there is a cardiologist working in one of the surgeries, it is obvious that the patient with complaints in the chest will be examined by him/her, in spite of fact that a case like this can be treated by everyone working there. So we suppose that each doctor going to the table with the envelopes has a specialist examination on emergency medical treatment. The selection in the first round is done by the HiFo system so the doctor chooses the case with the highest emergency grade. It is a small but solvable contradiction that the highest grade is the grade I and as this number rises so the grade of the emergency decreases. What happens in case of equal points? Then they change to the FiFo system which means from cases with the same emergency grade they choose the one which arrived earlier. Our patient who has a stomachache and was sorted to the grade IV has to wait until each case with grades I, II, III and also those who arrived earlier are examined. Naturally, each patient with grades I, II, III who arrives in the meantime changes this potential order. After our patients gets into the surgery which actually takes around an hour the doctor queries her, uploads the anamnesis into the computer, examines her and then takes notes about the present status of the patient. Then, he/she tries to arrange the necessary examinations. While the assistant takes a specimen of her blood, the doctor orders the laboratory tests via the computer system. It is the hospital porter who carries the test-tubes with the blood to the hospital's central laboratory from where the results will be shown for the doctor on the computer. Besides, the doctor sends the woman to an abdominal ultrasonic examination because of the pain in her stomach. He/she orders the desired examination via the computer network, the patient is accompanied by the hospital porter to the hospital's radiology where they complete the examination, and then the doctor can see the results on the monitor, ideally even when the patients is again in the waiting room of the department. Obviously, during these examinations the doctor begins other cases, as well, since there should be no dead time, so it can easily happen that the doctor treats five or six patients at the same time. Obviously, it means that the female patient with a stomachache cannot enter to the doctor immediately after arriving back from the ultrasonic examination, since he/she queries or examines the other (third or fourth) patient and arranges the next steps of his/her diagnostics. For the patient it is naturally a wasted time and probably not the only one. When she enters to the doctor again, he/she knows the results though he/she cannot close the case and asks for a medical consultation with a surgeon. While she waits for the specialist, she sits in the waiting room and the doctor is occupied with the next patient. When the surgeon arrives, the woman enters the surgery again; they examine her stomach, but do not find a severe, urgent inflammation or intestinal obstruction. The patient takes a seat in the waiting room again. Her emergency practitioner is aware of each information after the surgical consultation to state that the present menstrual spasms, revealed at the time of anamnesis, are in the background of the symptoms, so after the necessary documentation the patient can leave for home.

\subsection{The second case}

Our second patient is a man in his sixties whose side, while raking in their garden in Dunaújváros, weakens unexpectedly and then he falls down. His wife runs to him but the man can neither understand her words nor talk though he is seemingly attentive. She calls the ambulance that arrives to him in a short time. After assessing the patient's status they have to decide where to take the man. Before the era of emergency departments, the one-gate patient traffic the paramedics had to decide which hospital and which department they should take this man. It is an easier decision where the out patients' departments were within the same 
building, or in a fortunate case, next to each other but for example, in the clinic of the University of Szeged the department of neurology is not even in the same campus than those of surgery or internal medicine [6]. The system of one-gate emergency departments surmounts this situation where, regardless of what symptoms the paramedics observe, they take the patient directly to the EMD and the specialists are asked to go there to examine the case. Anyway, it is only the psychiatry which does not belong to this system for several professional reasons. In the present case, in this system, which does not cover the whole country, the paramedic has to decide where to take the patient for completely another reason. Using his professional experience and knowledge he/she assessed that they man has stroke. While the general neurologic care is accessible in most hospitals countrywide, so is in the hospital of Dunaújváros, but the stroke centre which gives a specific therapy - using systematic intravenous thrombolyses - can be found in Székesfehérvár, as the nearest. So the paramedic decides and goes directly to the Town of Kings. At the arrival the paramedics say that they have brought a patient and the triage nurse immediately sorts him as grade I. After a doctor examines him and ascertains that the symptoms started fifty minutes before, he starts to arrange the aforementioned lyses which has to be given to the patient within 4,5 hours. It is when the logistic race with the time starts. Preparing for the lyses, the patient is taken to the intensive department of the EMD. It is important to mention here that the process detailed as follows is accomplished even though a part of the candidates for the lyses does not get the treatment because of the contraindications revealed during the process. Now, I will not detail these professional principles. They take a specimen of the patient's blood for the further laboratory tests in the intensive department of the EMD. Meanwhile, a cranium CTexamination is asked in agreement with the cardiology, where the hospital porter takes the patient and the doctor working in the intensive department calls the neurologist working in the building three hundred meters away from him/her. By the time the neurologist finishes the call, the CT-images are in the computer system, in an ideal case, so he/she can observe them. If he/she sees bleeding, the lyses is contraindicated and order the patient to the department. The hospital porters take the patient with vehicles for ambulance service between the buildings, so he leaves the emergency department. If no bleeding can be seen on the $\mathrm{CT}$, the neurologist heads to the emergency department. He/she examines the patient and the laboratory results and decides if the lyses can be started. If so, the patient will stay in the intensive department of EMD for the following 24 hours. The dosage of the specific medicine is followed by the time of observation of this length. Then, a new cranium CT-image is taken then the patient is taken to the neurology department by the aforementioned hospital porters and their vehicle.

\subsection{Solutions}

In the cases detailed above the improvement of the logistic system is of more components. In the first case, the purpose is to decrease both the waiting time and the burden put on the doctors working in the department. In the second case, the main point is to allow the patient to have the specific therapy as soon as possible due to the extremely time-sensitive factor of the treatment.

Decrease of the waiting time is a crucial issue in other hospitals abroad, as well. Some of them present this data as the most important value of the patient's satisfaction. The Dutch University of Twente in Enschede set as an aim in their 2012 study that they intend to decrease this value in opposition of the principle that development of the network of medical advisers can relieve the emergency departments thus lessening the waiting time. They started from factors which they can influence by the structural and organizational transformation of the local EMD. They found out that a simple method like the practice that it is the triage nurse who orders the necessary laboratory tests lessened the gross (the total) waiting time with almost 9,5 minutes [2]. It increased the time spent at the triage nurse with only one and a half minute. The same study emphasizes the simple fact that the practical outlay of the EMD can decrease the waiting time, too. It is easy to imagine that the neurological consultation is slower in the hospital of Székesfehérvár since the neurologist starts from a street-like distance than if there were a neurologist working steadily in the emergency department. On the basis of similar principles, the Dutch study underlines the importance of surgeons as they have observed that they are needed for the $54 \%$ of the cases. [2] Though there is no similar survey in the Saint George Hospital, the workers in the EMD think that this high rate is not experienced there. Forcing the defensive medicine back would decrease the waiting time but it also would have a financial consequence, too. The menstrual spasm of the female patient with a stomache seemed to be potential even at the time of anamnesis; nevertheless she was given a thorough examination.

In case of our elderly male patient with a stroke the change in logistics may arise in a completely different field, actually in the ambulance level. Since it can easily be asked if the paramedics recognize the situation, namely the patient has embolism in the brain and has to be taken to the stroke centre, why should not they 
transport him directly to the hospital? Probably, the requirements according to the professional rules are provided in a better level in the intensive unit of the emergency department. Would not it be worth improving the infrastructure in order to decrease the loss of time?

These are special cases, however, in general we have to refer back to the roots of the problem, namely to the basic health care. The Hungarian studies on this subject claim without doubt that the present emergency service is not efficient the reason for which have multiple sides. Among others, the number of groundless claims is high which happens because the population is under informed and they have a kind of 'I deserve it'-attitude [4]. The professionals often experience parallel alarms when both the doctor on duty and the ambulance are called at the same time. Turning back to the professional field, the study finds the number of the present professional principles low. A well-formed protocol which meets the highest professional requirements can certainly improve the service [1].

\section{SUMMARY}

The present emergency medical attendance is not efficient enough according to both the Hungarian and international specialized literature or at least it could be organized in other forms. Simple modifications, like that the triage nurse orders the laboratory tests, can improve the efficiency to a greater extent, other developments of large volume like for example, the transformation of the system of family doctors would increase efficiency in an unacceptable degree. We think that one of the most striking problems is that the present emergency departments have been established in old building complexes. It means that the disunity of the specialized areas of medicine - for example the distance of the neurology department from the main building in Székesfehérvár - results in serious logistic problems for both the doctors and the patient.

\section{REFERENCES}

[1] Dózsa Csaba, Belicza Éva, Berényi Tamás, et al (2006), A hazai sürgősségi ellátás fejlesztésének programja, http://www.msotke.hu/downloads/szakmai/surgossegi_program_2006.pdf 2014.05. 08.

[2] Elderman, H. J. (2014), Improving patient logistics at the Emergency Department Leyweg of Haga Ziekenhuis: A quantitative analysis to reduce waiting times, http://essay.utwente.nl/61487/1/MSc_H_Elderman.pdf 2014.05.08.

[3] Kalabay L. (2008), Sürgősségi betegellátás, Mátrix, Budapest

[4] Müller, S. (2007), Sürgősségi esetek, Memorix, Semmelweis Kiadó, Budapest

[5] Sirák A. (1998), Sürgősségi betegellátás, SOTE, Budapest

[6] Tipsord, B. - Klinkhammer, C. P. (2000), Sürgősségi kórképek - Felismerés, ellátás, ápolás, Medicina Könyvkiadó, Budapest

[7] Fejér County Saint George University Teaching Hospital http://onkormanyzat.Székesfehérvár.hu/index.php?pg=news_67021 2014.05.08.

[8] The entrance to EMD http://www.fejer.hu/index.php?pg=news_1_1831 2014.05.08 